\title{
Modern Trends and Practices of E-Marketing: An Overview
}

\author{
Anupam Banerjee ${ }^{1}$ \\ ${ }^{I}$ (Deputy Manager-Corporate Planning, Globsyn, Kolkata)
}

\begin{abstract}
With the unprecedented growth of technology in global world, internet plays a paramount role in all the major areas of our life and industries. With-in few clicks we can explore ample information which will help in conceptualizing many tasks in nanoseconds and realizing this power of internet, marketing is not far behind to use it as a driving channel to reach the global territory. e-Marketing also known as digital marketing comprises the usage of virtual digital space with a scope of interaction, this digital space is been used by the marketer to promote and sell the products and services. This internet based marketing played a pivotal role to uplift the different economic sectors with special emphasize on marketing. Considering this is a cost effective, fast and flexible way to reach the audience of global Diasporas, e-marketing bring substantial business gains. However e-marketing has its own sets of limitations that include more of tech touch instead of personnel touch, ensuring the safety and security with aspect of privacy infringement. The paper starts with defining the concept, origin, how different e-marketing is from traditional marketing, 7 C's of e-marketing, different strategies of e-marketing the advantages, limitations, its future and conclusion.
\end{abstract}

Keywords: cost, global, internet, marketing, online.

\section{INTRODUCTION}

'Over the years marketing' and its ways to reach the global world is transformed and the key role in this transformation has been played by internet. The easy availability of Internet has led to progressive and interconnected environment, and the phenomenal growth of Internet has resulted in the declining trends of traditional media which primary covers the usage of television, radio, print media, banners and large hooding. Marketing in this closely connected environment and using this connectivity to market the products and services is e-Marketing. e-Marketing incorporates a wide spectrum of strategies and methods, but the basic fundamental of successful e-Marketing is a user-friendly and well designed approach to these strategies. E-marketing includes the management of the consumers real time online viability of the product, from first online experience through purchase to delivery of the product and the respective service beyond delivery .One of the major benefits of electronic marketing is the underlying messages are not restricted by geography or time. This paper has been divided into ten parts , Introduction, Concept, Origin, How Different From Traditional Marketing, The 7'Cs of EMarketing, Different methods of online marketing, its advantages and limitations, future developing trends of electronic marketing and Conclusion.

\section{CONCEPT}

E-marketing often referred as online marketing or internet marketing is a marketing technique where we are channelizing the marketing and promotion online with the aid of internet that further incorporates online advertising, using emails and social networking for promotion, here every aspect is been marketed and promoted online and in totality connected to distribution and sales. With major focus on global reach, e-marketing comprises information management, public relation and customer service with immediacy effect where the response from the set of customers can be obtained in an immediate real time, e-marketing improves a two way communication between the companies and the customer with cost minimization and speeding up the buying cycle with creating immediate leads for business expansion .E-marketing helps to understand and target the niche market by knowing their requirements well and delivering the same with lesser time and cost. 


\section{ORIGIN}

Though the very first interconnected computer was developed by US military in 1969, network email came into existence in 1974 and subsequently the online protocols were rolled out in 1980.In early 1990's Tim berner lee released the URL protocol and World Wide Web to public. Initially the usage of internet was restricted only for education and non commercial purpose but by 1995, these restrictions were dissolved. Yahoo and Amazon were the early players and launched their online platform in the meanwhile Google launched in 1998 and other auction sites like e-bay began to create their mark in the web domain. With the development of dotcom phenomenon and advancement of web 2.0 induced the beginning of social networking and simplified the process of creating and customizing the online pages and thus gave a big push to marketers to advertising their products online with an aim to reach global market and serve the target customers in a faster manner with lesser price and real time feedback mechanism.

\section{HoW DifFERENT FROM TRADITIONAL MARKETING}

If we compare the methods of online marketing with conventional traditional marketing practices, then there are ample areas and opportunities where online marketing is competent and have its advantages.

- Unlike traditional marketing where we have to wait for stipulated time frame to find out the response from the customers, online marketing is real time.

- Since we can the response of the customers in real time, it is easier to track if a particular campaign is working for the product or not and based on the feedback marketer can made the appropriate changes in the promotional campaign, in traditional marketing this flexibility is not possible.

- In traditional marketing, it is difficult for small retailers to compete with the big competitors in the market owing to the cost involved and strategy making expertise whereas in case of online marketing, through a crisp website you can reach your target audience with wider reach with better service assurance.

- Cost involvement is another point which creates a lot of difference between the conventional marketing techniques over online marketing; business house can create its respective digital marketing strategy with very little cost and replace conventional costly advertising methods such as print media, radio coverage, television and magazine.

- Through online marketing any business promotional idea have far greater reach and coverage as it can be seen any part of the world via one marketing campaign in optimal cost compared to conventional marketing campaigns and once any marketer optimized the important word search criteria content in website then it is a great return on investment with very marginal cost to maintain the positioning.

- With electronic marketing, marketer can create options to stimulate their target audience to take favorable appropriate action, visit the respective website, to know about their products and its features and different services, by this mechanism customers can express their view about the product, their choice of buying the product and corresponding feedback, which is also visible in the website thus by this way the marketer get an effective opportunity to engage with the customers, which is usually diluted in case of traditional mode of marketing.

- Through online marketing brand development can be done better than traditional mode of marketing, a well designed website with quality information can target the requirement of the customers and add significant value to their expectations with creation of greater opportunities.

- Online marketing has the potential to create ripple and viral effect in promotion over traditional mode marketing, for an instance using social media networking website, email and social media channels promulgates the content of the message to be shared incredibly quickly. 


\section{THE 7C'S OF E-MARKETING}

The $7 \mathrm{Cs}$ are basic pillars to understand the working and effectiveness of digital campaigning and helping business venture to transform from basic web based presence to a favorably prosperous e-venture. All these basic pillars are influential in creating the overall master plan of the business venture and help them to develop the socio economic model for the business based on the implementation of digital content and respective marketing. By implementing internet, the entire sales process can be executed in one format that too in an instantaneous manner. Digital marketing aware the target customers with additional information about the product starting from its features and feasibility which create impulse to execute the final purchase .Presently different techniques are available to create awareness among the customers and subsequently they have wide area of choice to select the product based on the price-feature index and likely to make the purchase. The bases of 7Cs of e-marketing are:

- Contract of the online campaign: The first and foremost rule of e-marketing is to develop and communicate the basic promise to the target customers about the value proposition offered by the respective e-marketer.

- Content of the campaign: refers to the content that will appear on the digital space, the content material has to be decided judiciously considering the fact, the content decide the mere browsers to possible buyers.

- Construction of the campaign: It is important that the contract communicated by the e-marketer is translated into appropriate interactive functionalities along with the web based features so that the target customers have an overall wonderful experience which will also ensure greater participation and sales.

- Community of the customers: Through proper digital space designing and creating appropriate awareness; e-marketers can create their own set of core customers, which in turn will act as the marketers for their website site.

- Concentration of consumer interest: Through online feedback mechanism of behavioral interest of the customers, e-marketers know, how behavior targeting is an important aspect to know the interest of the customers in terms of demographics pattern and apparently this information will help marketer to come out with a product align to customer interests, also past online purchase experience records of the customers helps marketer to come out with a better product promotion strategy.

- Convergence of the promotion: With the development in broadband technology and its appeal to the masses, e-marketing is working on a model to converge the online web based applications with direct marketing practices which not only minimize the cost of promotion but also increase the reach for global market. The advancement of broadband will help to develop new ways of advertising in terms of creativity and also enhance the features in traditional marketing practices

- Commerce of the campaign: The last and important principle of e-marketing is commerce, comprises the way of offering products/services to customers either directly or marketing those to another company on the basis of a fee agreement, which helps them to cover the fixed costs involved like site operations and cost of client acquisition.

\section{Different Methods Of E-Marketing}

E-marketing or online marketing can be executed and promoted by the following techniques and methods

- Online Advertising: This is the most known technique which is followed under e-marketing, where the marketer uses virtual space to convey and promote the marketing content on exclusively designed web pages to attract the attention of the internet users, here the major objective is to increase brand awareness and propagate sales. This method involves promotional messages on computer screen, it is more like a TV commercial but online campaigns are more creative.

- Mobile Marketing: Increasing features in smart phones created an opportunity for the customers to use and connect with online possibilities of advertising .Advancement of technology in mobile phones increases the avenues for mobile marketing in random fashion. The trend of mobile marketing has been 
welcomed by restaurants and movie theaters and with each passing year banks and financial institutions also using this method of marketing.

- E-mail marketing: This mode of online marketing is considered one of the most effective way of emarketing where emails are being used for sending promotional messages to internet users. The major benefit of this method is lower costs and broader reach but this method has its limitations as the online customer can easily ignore the received advertising content or the customer can put these emails in a spam folder.

- Video Marketing: In this mode of e-marketing, video is been added to the website to increase the website traffic in higher rate. In this mode, it is important that the relevant message need to be conveyed to the target audience thus the video needs to be designed in a manner where it will be able to understand and explain the needs of the customer else the entire initiative will be futile.

- Power of Blogging: Over the years, blogging is very much popular across the globe with no barrier of age groups, through blogging public can express their views and thoughts and this particular feature of this method is been monetized by marketers where small enterprises presenting and marketing their ideas in minimal cost price.

- SEO (search engine optimization): This method is more like an art of creating web traffic to the desired websites and this can be achieved by adopting the techniques to place the websites in higher ranking in the search engine websites thus ensuring greater amount of visitors.

- Affiliate marketing: It is package of online marketing methods where different website owners come together and build their networking relationship to increase their market reach and financial benefits. In this method specialized kind of software's being used to reward their affiliate for every site visitor.

- Social media marketing: This technique create brand awareness and boost the product by using social networking sites by creating unique content that attracts the attention of the social networking users and they share it with their set of friends.

- Corporate Video: This method comprises the usage of online interactive video and thus more successful to convey the desired message to the target audience and have the feature of easy sharing and cost effective in terms of creation and can be accessed across the globe.

\section{AdVAntages OF E-MARKeting}

Over the years e-marketing became the preferred way of conducting and promoting business in order to cut expenses, and increase the business profitability which is unlike in case of traditional marketing methods which emphasize on mass marketing. Electronic marketing method can be designed in such a manner to reach target set of customers or niche customers having specific expectation and preference for the products or services apparently based on the specific digital marketing campaign promotion, apart from the expenses cost and its reach another factor which make e-marketing more vibrant is its flexibility and its quality adherence, Online media is instant and round the clock available for usage for example a marketing promotion via a website is accessible 24/7, the message is keep on reinforced and any kind of changes in the content can be updated in real time with no geographical barriers. E-marketing ensures better quality check in terms of measurability and usage tracking. In traditional marketing methods since there is very limited scope for the advertiser to connect with customers unlike in emarketing engagement with target customer in real time is the key which in turn help the advertiser to know the customers and their needs well.

\section{LIMITATIONS OF E-MARKETING}

One of the biggest limitations of e-marketing is its reach and functioning is restricted by the ability of the consumer to access and use Internet services. Though over the years the importance and usage of Internet increases manifold in the community of developed and modern world still a substantial strata of consumers are unable to make 
use of internet or very limited access to it, especially in the rural areas. Security and privacy is another concern area in e-marketing with equal danger of being copied by the competitor as the level of competition is quiet huge in emarketing credit goes to lower cost in creation and vast reach. The content and the message should be very clear in online promotion campaigns else it may lose the underlying product with negative feedback from the customers which may hamper not only the marketing promotion but also damage the overall brand value.

\section{FUTURE OF E-MARKETING}

The future of e-marketing is promising, with the extension and power of social networking sites, the virtual scope of marketing is lucrative in terms of opportunity and option creation for global audience and providing service in customer doorstep in cost effective manner, though the different methods of online marketing is already been covered, the advancement of technology make the future of online marketing very promising with the following future trends in place

- Mechanism of Cost per click - Considering the major portion of online marketing promotion put towards the usage of digital technology, the scalability and effectiveness of advertisement is more profound in this method. Though there is a risk that market will become overburdened however with trend of inflation this method is profitable.

- Model of Cost per action buying -This digital advertising technique is upcoming and is the key focus area for online advertisers as $50 \%$ of promotional budget is been associated for these trends owing to the potential of reaching maximum amount of customers independent of location

- Verticalisation is going to be an effective and well strategized e-marketing trend where marketers target their specific audience. The concentration area in this technique is niche customers and for them the marketers come out with the strategy to deliver the specific message to its set audience.

- With increase in the options of online display, its combination with search marketing is going to be a popular trend. Through this mode of e-marketing the users who are accessing the website become a customer and considering the cost optimization with this method, the return of investment for the marketers is better and promising.

\section{CONCLUSION}

Internet has emerged as a revolution in overall aspect of our life starting from broader economy to marketing. This study reflects the concept of e-marketing with current strategies and its superiority over traditional marketing with set of advantages comprises wide coverage of global population, reaching the target set of customers and to get respective feedback from them about the product thus creating greater opportunity to engage with them with quick and effective results in optimal cost and scalable result. However using Internet in the marketing advertisement and promotions have their set of roadblocks, primarily that involves, being easily copied by the competitor, technology dependence, difficult to create serious perception, too much competition in limited space, brand value can be diluted by negative feedback, not easy to be absorbed by all people and developing the trust. With each passing day as the Internet is evolving, latest technologies and different marketing strategies will emerge in the electronic platform of marketing and redefine how different and new products and services will be marketed in a unique fashion in the coming days. With better understanding of the potential of electronic marketing with equal holistic consideration of its advantages and limitations will prepare corporate, entrepreneurs and digital marketers to face the challenges in the coming years.

\section{REFERENCES}

[1] Bart et al, Advertising and Promotion, An Integrated Marketing Communications Perspective, 2005.

[2] Russell Brunson, DotCom Secrets, 2015.

[3] Jay Baer, Youtility, 2013.

[4] D. Ryan, "Understanding Digital marketing", Marketing strategies for engaging the digital generation, 2014. 
IOSR Journal of Business and Management (IOSR-JBM)

e-ISSN: 2278-487X, p-ISSN: 2319-7668

[5] G. E. Blech and M. A Blech, Advertising and Promotion, An Integrated Marketing Communications Perspective $\left(9^{\text {th }}\right), 2012$.

[6] J. A. Davis, How Branding Adds Value United Kingdom, Competitive Success: John Wiley and Sons, 2010.

[7] D. whitely, E-commerce: Strategy, Technologies and Applications,(USA: Mc Graw-Hill, 2000).

[8] V. Yurovskiy, "Pros and Cons of Internet Marketing", Business administration, Turiba University, Latvia, 2010.

[9] J. H. Littell, J. Corcoran and V. Pillai, Systematic Reviews and Meta-Analysis, (USA: Oxford University Press, 2008). 